\title{
PENGARUH VARIASI PENGADUKAN SERBUK ALUMINIUM (AL), MAGNESIUM (MG), DAN SENG (ZN) TERHADAP SIFAT MEKANIK LOGAM DENGAN METODE METALURGI SERBUK
}

\author{
Mahadi S.T., M.T ${ }^{1}$, Rayhan Novri' ${ }^{2}$, \\ 1)Dosen Jurusan Teknik Mesin, Fakultas Teknik Universitas Sumatera Utara \\ 2) Mahasiswa Jurusan Teknik Mesin, Fakultas Teknik Universitas Sumatera Utara \\ Jl. Politeknik, Gedung J17 Kota Medan, Sumatera Utara \\ Email: dtm@usu.ac.id Telp: 081360766774
}

\begin{abstract}
The use of aluminum is often found The mechanical properties of aluminum that are lightweight and rust resistant are among the reasons aluminum is often used for certain raw materials. However, the mechanical properties of aluminum if the levels are pure will not be suitable for the purpose of use, because the value of hardness is very small. Therefore aluminum to add mechanical properties need to be added to other alloy compounds. This study focused on the addition of magnesium (Mg) and Zeng ( $\mathrm{Zn}$ ) alloys with 3 variations, namely the first variation of aluminum 100\%, the second variation of aluminum $95 \%$, magnesium $2.5 \%$, zinc $2.5 \%$, third variation of aluminum $90 \%$, magnesium $5 \%, 5 \%$ zinc. From the results of the hardness test, tensile test and impact test, the highest value is found in the third variation. Whereas for the third specimen metallographic test porosity occurs slightly due to the uniformly distributed filler and matrix
\end{abstract}

Keyword: Powder Metallurgy; Mechanical property; Aluminum; Magnesium; Zinc;

\section{PENDAHULUAN}

Penggunaan aluminum sering dijumpai Sifat mekanik aluminium yang ringan dan tahan karat menjadi salah alassan alumunium sering digunakan untuk bahan baku tertentu. Namun sifat mekanik alumunium jika kadarnya murni akan tidak sesuai dengan tujuan pengguaan, karena nilai kekerasannya sangat kecil. Maka dari itu aluminium untuk menambah sifat mekaniknya perlu ditambahkan senyawa senyawa paduan lainnya

Pada penelitian sebelumnya Mugiono[1] meneliti pengaruh penambahan mg terhadapa sifat kekerasan dan kekuatan impak serta struktur mikro pada paduan alumunium berbasis piston bekas. Penilitian tersebut bervariasi antara $\operatorname{Mg}(0 \%, 5 \%, 10 \%, 15 \%)$. Penelitian tersebut membuktikan bahwa terjadi peningkatan hasil uji kekerasan dan hasil impak setiap penambahan magnesium. Hasil uji membuktikan bahwa semakin bertambahnya magnesium struktur semakin rata sehingga sifat mekaniknya meningkat.

Penambahan unsur seng (Zn) yang dilakukan oleh Bondan[2] pada Al-Zn-6Mg mempngaruh sifat mekanik. Penambahan Zn dari 5 wt\% menjadi 9 wt\% menghasilkan peningkatan kekerasan dan terjadi prose pengerasan pengendapan sehingga akan meningkatkan ketangguhan impak komposit[2] 
Berdasarkan senyawa unsur kimia magnesium dan seng yang dapat meningkatkan sifat mekanik alumunium maka penulis mencoba melakukan penilitian dengan judul "Pengaruh Variasi Campuran Serbuk Aluminium (Al), Magnesium (Mg), Dan Seng (Zn) Terhadap Sifat Mekanik Logam Dengan Metode Metalurgi Serbuk”

\section{TEORI DASAR}

\subsection{Metalurgi Serbuk}

Metalurgi serbuk adalah metode yang terus dikembangkan dari proses manufaktur yang dapat mencapai bentuk komponen akhir dengan mencampurkan serbuk secara bersamaan dan dikompaksi dalam cetakan, dan selanjutnya disinter di dalam furnace (tungku pemanas)[3]

Prinsip ini adalah memadatkan sebuk logam menjadi bentuk yang dinginkan dan kemudian memanaskannya di bawah temperatur leleh. Sehingga partikel-partikel logam memadu karena mekanisme transportasi massa akibat difusi atom antar permukaan partikel. Metode metalurgi serbuk memberikan kontrol yang teliti terhadap komposisi dan penggunaan campuran yang tidak dapat difabrikasi dengan proses lain. Sebagai ukuran ditentukan oleh cetakan dan penyelesaian akhir Proses pemanasan yang dilakukan harus berada di bawah titik leleh serbuk material yang digunakan. Setiap proses dalam pembuatan metalurgi serbuk sangat mempengaruhi kualitas akhir produk yang dihasilkan

\subsection{Komposit}

Material komposit didefinisikan sebagai campuran makroskopik antara serat dan matrik yang bertujuan untuk menghasilkan suatu material baru yang memiliki sifat dan karakteristik yang berbeda dari unsur penyusunnya.

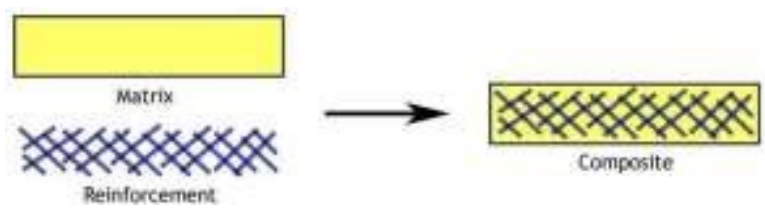

Gambar 2.1 Komposit

\subsection{Pengujian}

\subsubsection{Pengujian Kekerasan}

Pengujian kekerasan merupakan pengujian yang mengukur ketahanan suatu material terhadap adanya deformasi plastis pada suatu titik tertentu. Pengujian kekerasan adalah sederhana, sehingga banyak dilakukan dalam pemilihan bahan. Ada beberapa macam alat penguji kekerasan sesuai dengan: bahan, kekerasan, ukuran, dan lain - lain.Ada beberapa macam alat penguji kekerasan yang dipergunakan sesuai dengan: bahan, kekerasan, ukuran, 
dan lain - lain. Cara - cara pengujian kekerasan adalah sebagai berikut.

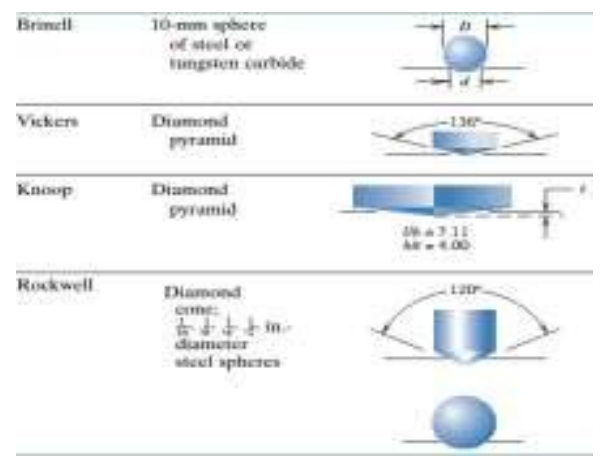

Gambar 2 Teknik pengujian kekerasan[4]

Didunia teknik, umumnya pengujian kekerasan menggunakan 4 macam metode pengujian kekerasan, yakni:

1. Brinell (HB/BHN)

2. Vickers (HV/VHN)

3. Knоop $(\mathrm{HK} / \mathrm{VHN})$

4. Rockwell (HR/RHN)

\subsubsection{Pengujian Tarik}

Untuk mengetahui sifat dari suatu material maka diperlukan suatu pengujian, salah satu pengujian yang paling sering dilakukan yaitu uji tarik (tensile test). Pengujian ini memiliki fungsi untuk mengetahui tingkat kekuatan suatu material dan untuk mengenali karakteristik pada material tersebut. Prinsipnya, uji tarik ini dilakukan menggunakan mesin yang dapat memberikan gaya tarik yang cukup kuat pada material dan juga memberikan cengkraman yang kencang sehingga material tidak terlepas ketika diberikan gaya tarik. Ada banyak hal yang bisa didapatkan dari uji tarik, dengan memberikan gaya tarik pada material sampai putus maka semua susunan struktur material bisa diketahui dengan jelas sehingga dapat menentukan kualitas dari material tersebut. Bahan atau material yang sering dijadikan objek untuk uji tarik adalah rubber dan logam. Kedua bahan ini memiliki sifat yang berbeda dari setiap prosesnya. Misalkan, sifat rubber dan logam sebelum dipanaskan pasti memiliki perbedaan ketika sudah dipanaskan. Penggunaan Hukum Hooke (Hooke's Laws pada Uji Tarik).Uji tarik memiliki prinsip dasar dari hukum hooke (hooke's law) dimana regangan (strain) dan rasio tegangan (stress) adalah konstan.Sehingga hubungan dari strain dan stress dapat dirumuskan menjadi[5] :

$$
\mathrm{E}=\sigma / \varepsilon \ldots(2.3)
$$

\subsubsection{Pengujian Impact}

Adalah pengujian dengan menggunakan pembebanan yang cepat (rapid loading). Dalam Pengujian Mekanik, terdapat perbedaan dalam pemberian jenis beban kepada 
material. Uji tarik, uji tekan, dan uji punter adalah pengujian yang menggunakan beban statik. Sedangkan uji dampak (fatigue) menggunakan jenis beban dinamik. Pada uji dampak, digunakan pembebanan yang cepat (rapid loading). Perbedaan dari pembebanan jenis ini dapat dilihat pada strain rate. Pada pembebanan cepat atau disebut dengan beban dampak, terjadi proses penyerapan energi yang besar dari energi kinetik suatu beban yang menumbuk ke spesimen. Proses penyerapan energi ini, akan diubah dalam berbagai respon material seperti deformasi plastis, efek histerisis, gesekan, dan efek inersia[6].

\subsubsection{Pengujian Metalografi}

Struktur mikro merupakan struktur yang dapat diamati dibawah mikroskop optik. Meskipun dapat pula diartikan sebagai hasil dari pengamatan menggunakan scanning electron microscope(SEM). Mikroskop optik dapat memperbesar struktur hingga 1500 kali.Struktur mikro suatu logam dapat diramalkan melalui diagram fasanya.Dengan melihat diagram fasa, kita dapat mengetahui komposisi daripaduan, dan juga mengetahui pada temperatur berapa butir akan tumbuh.Setelah benda uji sruktur mikro mengalami proses deformasi dan perlakuan panas, butir- butirakan mengalami perubahan bentuk dan ukuran[7] Melakukan pemolesan secara bertahap hingga lebih halus dari 0,5 mikron. Proses ini biasanya dilakukan dengan menggunakan ampelas secara bertahap dimulai dengan grid yang kecil (100) hingga gird yang besar (2000). Dilanjutkan dengan pemolesan oleh mesin poles dibantu dengan larutan pemoles[8].

\section{Metodologi Penilitian}

\subsection{Prosedur Penelitian}

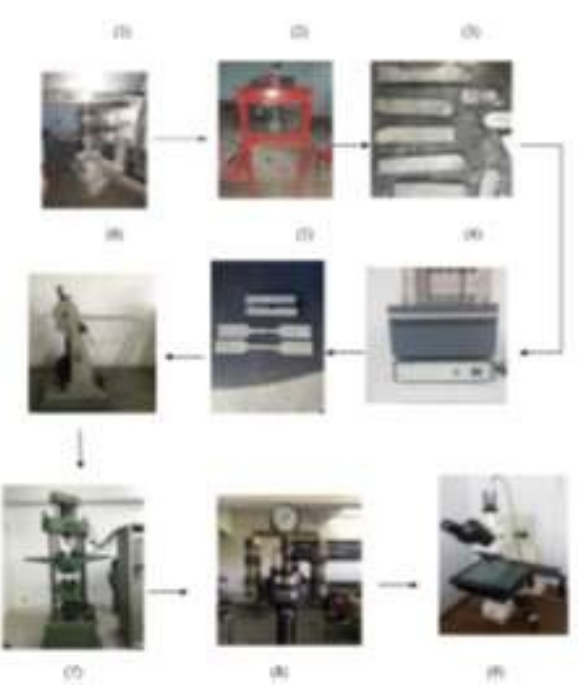

Gambar 4 Tahapan Penelitian \& Pengujian 
Keterangan:

1. Proses Pengadukan Serbuk

2. Proses Pencetakan (kompaksi)

3. Hasil Setelah dicetak

4. Proses Pemanasan (sintering)

5. Spesimen

6. Pengujian Impak

7. Pengujian Tensil

8. Pengujian Kekerasan

9. Pengujian Metalografi

\subsection{Prosedur Pengujian}

\subsubsection{Proses penimbangan serbuk}

Bahan yang digunakan untuk proses pembuatan metal matrix composite pada eksperimen ini terdiri dari serbuk aluminium, serbuk magnesium, serbuk seng. Masingmasing bahan tersebut akan ditimbang dengan menggunakan timbangan digital yang telah disediakan. Berikut prosesnya:

a. Timbang bahan aluminium $100 \%$.

b. $\quad$ Timbang bahan aluminium 95\%, magnesium 2.5\%, seng $2.5 \%$.

c. $\quad$ Timbang bahan aluminium $90 \%$, magnesium 5\%, seng $5 \%$.

\subsubsection{Proses Pengadukan Serbuk}

Proses pengadukan serbuk ini dilakukan di Laboratorium Foundri, Departemen Teknik Mesin, Universitas Sumatera Utara. Adapun prosedur yang dilakukan pada proses pengadukan serbuk ini adalah sebagai berikut:

1 Siapkan mesin pengaduk untuk proses pencampuran serbuk aluminium, serbuk magnesium dan serbuk seng yang sudah ditimbang sesuai kadar yang diinginkan.

2 Siapkan bahan yang sudah di timbang dan masukan ke wadah pengaduk untuk dicampur.

$3 \quad$ Hidup kan mesin pengaduk dengan waktu kurang lebih 30 menit, dan proses ini dilakukan sebanyak serbuk yang diinginkan

$4 \quad$ Setelah sudah tercampur masukkan kedalam wadah masing - masing sesuai variasi.

\subsubsection{Proses Kompaksi}

Spesimen akan di cetak dengan menggunakan mesin kompaksi. Campuran Aluminium, Magnesium dan Seng (100:0:0,95:2.5:2.5 90:5:5\%) dituangkan ke dalam cetakan, kemudian dilakukan proses compacting selama 10 menit dengan beban 10 ton. Kemudian setelah 10 menit cetakan diangkat dan dipindahkan dari mesin press. Dan serbuk 
yang sudah ditekan dikeluarkan dari cetakan dengan perlahan, agar bentuk tidak hancur karena masih bersifat rapuh tidak terlalu keras. Selanjutnya akan dilakukan proses sintering dengan suhu 570 derajat celcius dan selanjutnya akan dilakukan proses pengujian. Tekanan pemadatan yang diperlukan tergantung pada jenis serbuk yang digunakan, dalam hal ini aluminium memiliki nilai yang berkisar antara 70 - 275 Mpa (5 - 20 ton-force).

\subsubsection{Proses Sintering}

Serbuk yang telah dicetak pada mesin kompaksi dengan tekanan 10 ton selanjutnya akan disintering. Suhu sintering yang digunakan pada penelitian ini adalah $90 \%$ dari titik leleh alumunium yaitu pada suhu 570 detajat celcius dengan waktu penahanan sintering dilakukan selama 2 jam menggunakan furnace. Setelah 2 jam specimen dikeluarkan dari furnace dan specimen dibiarkan hingga suhu ruangan, pada tahap ini specimen sudah mengeras dengan baik, selanjutnya akan dilakukan proses machining, untuk menyesuaikan ukuran dengan ASTM untuk dilakukan pengujian.

Untuk material komposit, temperature sinter yang digunakan adalah temperatur sinter dari matriks sebesar 70\%-90\% dari titik lebur bahan, dalam hal ini untuk bahan aluminium dengan titik lebur $660^{\circ} \mathrm{C}$, temperatur sinternya berkisar antara $460^{\circ} \mathrm{C}$ hingga $590^{\circ} \mathrm{C}$.

\section{HASIL DAN PEMBAHASAN}

\subsection{Hasil Uji kekerasan, Hasil Uji Tarik dan Hasil Uji}

\begin{tabular}{|c|c|c|c|c|c|c|}
\hline Yม่ม่ & Itis & Fulpl) & $D(m a)$ & diani) & BHN & Avg \\
\hline \multirow{5}{*}{ A 1005} & 1 & 900 & 5 & 37 & 499 & \multirow{5}{*}{465} \\
\hline & 2 & 500 & 5 & 18 & 424 & \\
\hline & 3 & 500 & 5 & 33 & 503 & \\
\hline & 4 & 590 & 5 & 15 & 503 & \\
\hline & 5 & 900 & 5 & 17 & 449 & \\
\hline \multirow{5}{*}{$\begin{array}{l}\text { Al9s } \\
\text { Net25s } \\
24258\end{array}$} & 1 & 900 & 5 & 32 & 605 & \multirow{5}{*}{514} \\
\hline & 2 & 900 & 5 & 3.7 & 449 & \\
\hline & 3 & 900 & 5 & 35 & 503 & \\
\hline & 4 & 500 & 5 & 39 & 49 & \\
\hline & 5 & 900 & 5 & 33 & 561 & \\
\hline \multirow{5}{*}{$\begin{array}{l}\text { N9\%5 } \\
\text { Mq56 } \\
2496\end{array}$} & 1 & 500 & 5 & 30 & 691 & \multirow{5}{*}{ S.2. } \\
\hline & 2 & 500 & 5 & 32 & 603 & \\
\hline & 3 & 900 & 5 & 29 & 761 & \\
\hline & 4 & 500 & 5 & 12 & Gis & \\
\hline & 5 & 500 & 5 & 3.3 & 568 & \\
\hline
\end{tabular}

Tabel 1 Hasil Uji kekerasan

\begin{tabular}{|c|c|c|c|c|}
\hline Yrai & 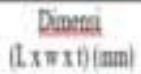 & 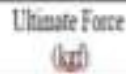 & 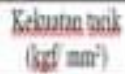 & A溇 \\
\hline \multirow{5}{*}{ N I I I S } & $5 \times 63 \times 3$ & 156.14 & 8.26 & \multirow{5}{*}{3.41} \\
\hline & $28 \times 63 \times 3$ & 16650 & 8.81 & \\
\hline & $3 \times 63 \times 3$ & 1525 & 7.9 & \\
\hline & $25 \times 63 \times 3$ & 16102 & 39 & \\
\hline & $25 \times 63 \times 3$ & 16465 & 8.89 & \\
\hline \multirow{5}{*}{$\begin{array}{l}\text { A } 955 \\
\text { Mq25\% } \\
2029 \%\end{array}$} & $25 \times 63 \times 3$ & 1967 & 10.11 & \multirow{5}{*}{10.12} \\
\hline & $25 \times 63 \times 3$ & 1598 & 1052 & \\
\hline & $25 \times 63 \times 3$ & 152.48 & 992 & \\
\hline & $25 \times 63 \times 3$ & $192+0$ & 10.18 & \\
\hline & $15 \times 63 \times 3$ & 18654 & 93 & \\
\hline \multirow{5}{*}{$\begin{array}{l}\mathrm{A} W \mathrm{~W} \\
\mathrm{M} 4 \% \\
\mathrm{Z} \%\end{array}$} & $3 \times 63 \times 3$ & 29.48 & 13.0 & \multirow{5}{*}{132} \\
\hline & $3 \times 63 \times 3$ & $2649 ?$ & 1402 & \\
\hline & $3 \times 63 \times 3$ & 39.68 & 1265 & \\
\hline & $35 \times 63 \times 3$ & 249.48 & 13210 & \\
\hline & $3 \times 63 \times 3$ & 2437 & 1291 & \\
\hline
\end{tabular}

Tabel 2 Uji Tarik 


\begin{tabular}{|c|c|c|c|c|c|}
\hline Variasi & $\begin{array}{c}\text { Dimensi } \\
(\mathrm{L} \times \mathrm{w} \times \mathrm{t})(\mathrm{mm})\end{array}$ & $\begin{array}{c}\text { Sudut Awal } \\
\left({ }^{\circ}\right)\end{array}$ & $\begin{array}{l}\text { Sudut Akhir } \\
\left({ }^{\circ}\right)\end{array}$ & $\begin{array}{c}\text { Energy } \\
\text { Impact (E) }\end{array}$ & Avg \\
\hline \multirow{5}{*}{ Al $100 \%$} & $55 \times 10 \times 10$ & 147 & 146 & 1.5 & \multirow{5}{*}{1.8} \\
\hline & $55 \times 10 \times 10$ & 147 & 146 & 1.5 & \\
\hline & $55 \times 10 \times 10$ & 147 & 145 & 3.1 & \\
\hline & $55 \times 10 \times 10$ & 147 & 146 & 1.5 & \\
\hline & $55 \times 10 \times 10$ & 147 & 146 & 1.5 & \\
\hline \multirow{5}{*}{$\begin{array}{c}\mathrm{Al} 95 \% \\
\mathrm{Mg} 2.5 \% \\
\mathrm{Zn} 2.5 \%\end{array}$} & $55 \times 10 \times 10$ & 147 & 145 & 3.1 & \multirow{5}{*}{2.7} \\
\hline & $55 \times 10 \times 10$ & 147 & 145 & 3.1 & \\
\hline & $55 \times 10 \times 10$ & 147 & 145 & 3.1 & \\
\hline & $55 \times 10 \times 10$ & 147 & 146 & 1.5 & \\
\hline & $55 \times 10 \times 10$ & 147 & 145 & 3.1 & \\
\hline \multirow{5}{*}{$\begin{array}{l}\text { Al } 90 \% \\
\text { Mg 5\% } \\
\text { Zn } 5 \%\end{array}$} & $55 \times 10 \times 10$ & 147 & 144 & 4.8 & \multirow{5}{*}{3.1} \\
\hline & $55 \times 10 \times 10$ & 147 & 145 & 3.1 & \\
\hline & $55 \times 10 \times 10$ & 147 & 145 & 3,1 & \\
\hline & $55 \times 10 \times 10$ & 147 & 145 & 3.1 & \\
\hline & $55 \times 10 \times 10$ & 147 & 146 & 1.5 & \\
\hline
\end{tabular}

Tabel 3 Hasil Uji Impact

\subsection{Hasil Pengujian Metalografi}

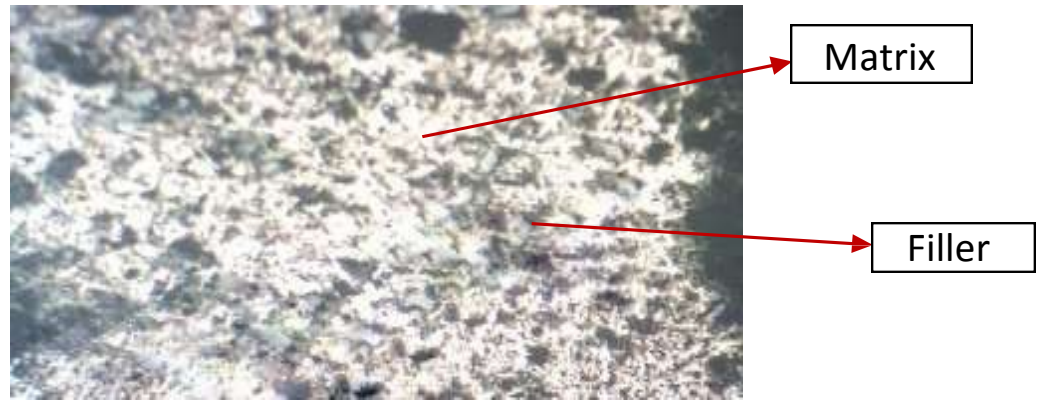

Gambar 5 Struktur mikro dengan variasi komposisi 1

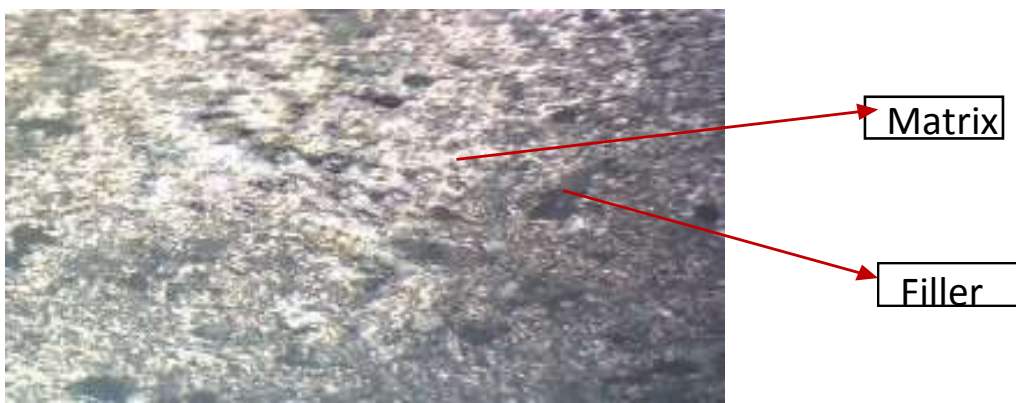

Gambar 6 Struktur mikro dengan variasi komposisi 2

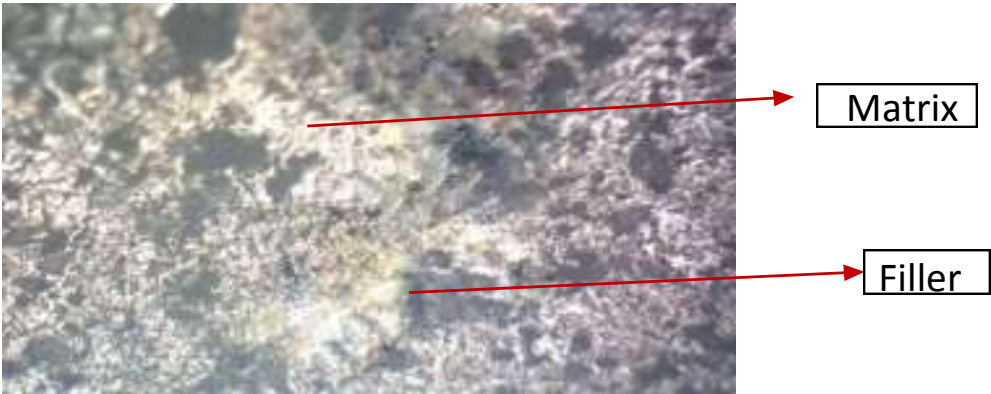

Gambar 7 Struktur mikro dengan variasi komposisi 3 
Dapat dilihat pada gambar 7 tersebut memperlihatkan hasil pengujian mikrosturktur pada pembesaran 100x yaitu campuran aluminium yang mengandung $\mathrm{SiC}$ dan 5\% magnesium dan 5\% seng. Dari gambar tersebut, terlihat perbedaan pada matriks dan filler, terlihat filler semakin banyak dibandingkan dengan gambar 5 dan 6 dan juga semakin banyak terjadi penumpukan. Nilai porositas pun lebih baik dari variasi 1 dan variasi 2

Porositas merupakan persentase perbandingan volume kosong (rongga) dengan volume benda padatnya. Ada dua jenis porositas, yakni porositas terbuka dan porositas tertutup. Pada porositas tertutup, rongga di dalam suatu benda tidak dapat ditembus oleh air, sehingga pengukuran porositas tertutup sulit dilakukan. Sedangkan porositas terbuka mempunyai akses dengan permukaan luar meskipun rongga berada di tengah-tengah benda. Pada pengujian mikrostruktur, dari gambar diatas dapat dilihat penyebaran pada penguat SiC, Mg dan Zn di setiap spesimen Metal Matrix Composite (MMC). Dari setiap variasi komposisi yang berbeda, semakin banyak pada campuran penguat Mg dan Zn maka semakin banyak penyebaran serbuk penguat terlihat pada foto mikrostruktur, sehingga nilai porisitas semakin kecil

\section{KESIMPULAN DAN SARAN}

\subsection{Kesimpulan}

1 Adapun hasil uji kekerasan, uji tarik dan uji impak setiap variasi spesimen diuraikan sebagai berikut:

a. Nilai kekerasan yang diperoleh paling tinggi secara rata rata adalah specimen dengan variasi 3 (Al 90\%: Mg 5\%:Zn5\%) sebesar 64.2 BHN dan nilai kekerasan terendah didapat pada spesimen variasi 1 (Al:100\% Mg 0\%:Zn0\%) sebesar 46,5 BHN .

b. Nilai uji tarik yang diperoleh paling tinggi secara rata rata adalah specimen dengan variasi 3 (Al 90\%: Mg 5\%:Zn5\%) sebesar $13.2 \mathrm{Kgf} / \mathrm{mm} 2$ dan nilai kekerasan terendah didapat pada spesimen variasi 1 (Al:100\%:Mg 0\%:Zn0\%) sebesar 8,4 Kgf/mm2.

c. Nilai uji impak yang diperoleh paling tinggi secara rata rata adalah specimen dengan variasi 3 (Al 90\%: Mg 5\%:Zn5\%) sebesar 3,1J dan nilai kekerasan terendah didapat pada spesimen variasi 1 (Al:100\%:Mg 0\%:Zn0\%) sebesar 1,8J

2. Dari hasil penelitian pembuatan komposit matriks logam berpenguat keramik Al dan silicon carbide melalui metode metalurgi serbuk, maka dapat ditarik kesimpulan bahwa :

1. Pada pengujian mikrostruktur didapat sebagai berikut :

a. Pada pengujian mikrostruktur dengan perbandingan komposisi variasi 1 (Al:100\%:Mg0\%:Zn0\%) dilihat pada gambar nampak perbedaan antara matrix dan filler tersebar dan juga terjadi porositas gambar

b. $\quad$ Pada pengujian mikrostruktur dengan perbandingan variasi 2 (Al 95\%: $\mathrm{Mg}$ 2,5\%:Zn 2,5\%) dilihat pada gambar nampak perbedaan antara matrix dan filler tersebar dan porositas yang terjadi lebih sedikit di bandingkan dengan variasi 1 (Al:100\%:Mg0\%:Zn0\%) 
c. Pada pengujian mikrostruktur dengan perbandingan komposisi variasi 3 (Al 90\%: Mg 5\%:Zn5\%) dilihat pada gambar nampak perbedaan antara matrix dan filler tersebar dan porositas yang terjadi lebih sedikit bandingkan variasi 2 (Al 95\%: Mg 2,5\%:Zn 2,5\%) dan variasi 1 variasi 1 (Al:100\%:Mg0\%:Zn0\%)

\subsection{Saran}

Pada penelitian yang sudah dilakukan, terdapat saran untuk proses penelitian lebih lanjut dalam pembuatan komposit matriks logam (MMC) aluminium menggunakan campuran magnesium dan seng disarankan :

1. Karena keterbatasan alat uji melaografi yang disediakan, diharapkan selanjutnya dapat menggunakan alat uji microscope test dengan pembesaran grid yang lebih baik.

2. Diharapkan penilitian ini menjadi tahap awal dari penilitian selanjutnya tentang pengembangan sifat mekanik paduan alumunium

\section{REFERENSI}

[1] Mugiono, Lagiyono, Rusnoto. Pengaruh Penambahan Mg Terhadap Sifat Kekerasan Dan Kekuatan Impak Serta Struktur Mikro Pada Paduan Al-Si Berbasis Material Piston Bekas.

Jurnal Teknik Mesin, 2013 :1-6

[2] Bondan Tiara Sofyan dkk. Pengaruh Penambahan Unsur Paduan Zn Terhadap Kinerja Balistik Komposit Matriks Al-Zn-6mg Berpenguat Partikel Silikon Karbida.Departemen Teknk Metalurgi dan material, Fakultas Teknik Universitas Indonesia 2012

[3] Nurun Nayiroh. "Metalurgi Serbuk" . http://nurun.lecturer.uin malang.ac.id/wpcontent/uploads/sites/7/2013/03/METALURGI- SERBUK.pdf (diakses 15/06/2019 pukul 17.00)

[4] Suresh, S., Mortensen A. dkk N..Fundamentals of Metal Matrix Composites, London: Butterworth - Heinemann;1993.

[5] William D. Callister. Materials Science and Engineering An Introduction 6th edition.

Singapore: Example Product Manufacturer;2003

[6] Smallman \& Bishop. Materials Science and Engineering 1st edition . Singapore: Butterworth-Heinemann;1995.

[7] Alamsyah, M. F. Laporan Praktikum Struktur Dan Sifat Mekanik,.Universitas Diponegoro, Semarang;2008.

[8] Randall M German.Sintering Theory and Practice.New York: Wiley-Interscience;1996 